https://doi.org/10.31713/m1111

\title{
SIMPLIFIED MODEL FOR DETERMINING ROCK MASS OSCILLATION VELOCITY AT LIMESTONE DEPOSIT
}

\author{
S. Lutovac \\ $\mathrm{PhD}$ (Engineering), Associate Professor, Faculty of Mining \\ and Geology, University of Belgrade, Serbia
}

B. Gluščević

PhD (Engineering), Full Professor, Faculty of Mining and Geology, University of Belgrade, Serbia

\section{Gligorić}

$\mathrm{PhD}$ (Engineering), Assistant Professor, Faculty of Mining and Geology, University of Belgrade, Serbia

\author{
J. Majstorović \\ $\mathrm{PhD}$ (Engineering), Research Associate, Faculty \\ of Mining and Geology, University of Belgrade, Serbia
}

R. Tokalić

PhD (Engineering), Full Professor, Faculty of Mining and Geology, University of Belgrade, Serbia

\begin{abstract}
As a way of exploitation in mining operation, mass blasting has the more application. However, usage the large amount of explosives leads to increasing the negative blasting effects. By the negative blasting effects, we mean seismic effect of blasting, sound effect, scattering of blasted rock mass, etc. In order to protect environment from shock when performing blasting it is necessary to define rock mass oscillation equation for each working site. This paper offers the analysis of the method for defining parameters of the oscillation equation. To define parameters in the rock mass oscillation equation, we have used five models. The first model represents a usual model - method of Least Squares. The second model is based on the quotient of the value of the equal number of experimental data of oscillation velocity and corresponding reduced distances. The third model is based on defining parameters of oscillation equation by applying Lagrange's theorem. The fourth model is based on defining parameters for oscillation equation by applying the quotient of relative oscillation velocity increments and reduced distances. As the result of numerous measuring's there has been noted that the value of one of the parameters in the oscillation equation is within the limits from 1 to 3 , however most frequently from 1 to 2 . On the basis of this as well as on the basis of oscillation equation characteristic, the value of one parameter was adopted. Thus, we got a new rock mass
\end{abstract}


oscillation equation which is now simpler, and we designated it as the fifth model. On the basis of calculation on concrete example of mass blasting, it has been stated that all mentioned models may be used in order to calculate rock mass oscillation velocity.

Key words: working environment, blasting, oscillation velocity, rock mass oscillation equation.

\section{Introduction}

Explosion caused by detonation of explosive is accompanied by liberation of a great quantity of energy. On that occasion, a part of that energy is used for the destruction of the rock. The other part of energy in the form of a seismic wave is lost in the massive, causing elastic deformations in the rock mass. These deformations at the site are manifested as impact. The impact may cause damage to the objects as well an unpleasant feelings and fear in people. Many authors have studied and proved that sensitivity of the human body to the blasting effects is more than 10 times greater than of sensitivity of the buildings [1-2]. By knowing the rock mass characteristics, status and type of potentially endangered structure, and blasting parameters, blasting works can be executed in a safe and secure way [3-5]. Controlling the seismic effects of blasting and reducing the negative effects are of great importance for the work safety and maintaining the regular production in open-pit mines [6-8]. Parameter for estimating of the seismic action of blasting, that is commonly used, represents the rock mass oscillation velocity.

As the relation between rock mass oscillation velocity and the basic parameters that influence its magnitude, most often is used the M.A. Sadovskii equation where oscillation velocity $v$ is given in the form o

$$
v=K \cdot R^{-n},
$$

where $R$ is reduced distance, that represents distance from the blasting site to monitoring site $r$, reduced to the total quantity of the explosive $Q$ i.e. $R=r / \sqrt[3]{Q}$. Parameters $K$ and $\mathrm{n}$ are conditioned by characteristics of the rock mass and blasting conditions. Thus, $v$ is a decreasing and convex function of the variable $R$.

\section{Recording rock mass oscillation velocity}


Intensity of the shock is measured by instruments - seismographs. Measuring of the rock mass oscillation velocity needed for this paper has been done by the instrument type Vibraloc, produced by the Swedish firm ABEM. From seismograph, maximum values for three oscillation velocity components can be recorded in directions $X, Y$ and $\mathrm{Z}$ from the rectangular coordination system, as follows:

$v_{\mathrm{t}}$ - rock mass oscillation velocity horizontal transversal component,

$v_{\mathrm{v}}$ - rock mass oscillation velocity vertical component,

$v_{1}$ - rock mass oscillation velocity horizontal longitudinal component.

Based on that, maximum, i.e. resulting rock mass oscillation velocity $v_{r}$ can be determined using following equation

$$
v r=\sqrt{v_{t}^{2}+v_{v}^{2}+v_{l}^{2}}
$$

In Fig. 1, the recording of oscillation velocity of the ground intended for blasting IV - measuring point 3 at Drenovac open pit is shown.

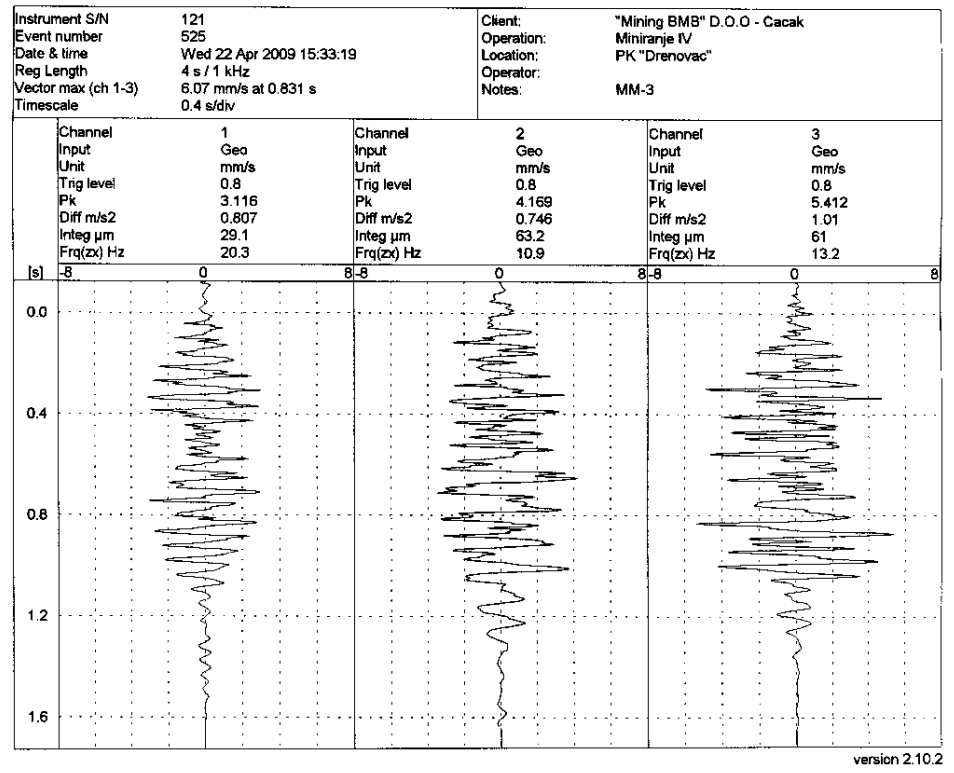

Fig. 1. Record of oscillation velocity of the ground intended for blasting IV - MP 3 


\section{Rock mass oscillation velocity equation}

Rock mass oscillation velocity equation defines velocity alteration of rock mass oscillation depending on distance, explosive amount, properties of rock material and blasting method. The equation, defined in this way, offers the possibility to determine the seismic effect of blasting towards a structure, whereby the connection, between the rock mass oscillation velocity and consequences that can affect facilities, is used.

The equation of M.A Sadovskii [9] is given in the form

$$
v=K \cdot R^{-n}=K \cdot(r / \sqrt[3]{Q})^{-n}
$$

where there are

$v$ - rock mass oscillation velocity $(\mathrm{cm} / \mathrm{s})$

$K$ - coefficient conditioned by rock mass characteristics and blasting conditions,

$n$ - exponent conditioned by characteristics of rock mass and blasting conditions,

$r$ - distance from the blasting site to the monitoring point (m),

$Q$ - total amount of explosive $(\mathrm{kg})$.

$R$ - the reduced distance, given in the form $R=r / \sqrt[3]{Q}$.

The Sadovskii equation is determined based on test blasting for the concrete working environment.

\subsection{Derivation the rock mass oscillation velocity equation}

The equation of Sadovskii was derived from the condition: if the radius of charge $r_{0}$ and distance from the blasting site to the monitoring point $\mathrm{r}$ increase in the same or approximately the same ratio, the rock mass oscillation velocity $\mathrm{v}$ remains the same [9-10].

Here we cite another manner of rock mass oscillation velocity equation derivation. If, in blasting in the specific environment, the relative increment in rock mass oscillation velocity and relative increment of reduced distance are monitored, then it can be seen that their relations at various levels have approximately the same value which will be marked $-n$ meaning that

$$
(\Delta v / v) /(\Delta R / R) \approx-n
$$

Thereby, it can be considered that 
$\lim _{\Delta R \rightarrow 0} \frac{\frac{d v}{v}}{\frac{d R}{R}}=-n$, which means that is $: \frac{\frac{d v}{v}}{\frac{d R}{R}}=-n$

Equation (5) can be written in the form: $\frac{d v}{v}=-n \cdot \frac{d R}{R}$, whereby integration, it is obtained

where $C$ is a constant of integration.

Equation (6) can be written in the form

$$
\log v=\log C \cdot R^{-n}
$$

If in the previous equation we use $C=K$, we arrive at M.A. Sadovskii rock mass oscillation equation.

\subsection{The property of the rock mass oscillation equation}

The rock mass oscillation equation, given in the Equation (1) may be written in the form

$$
v \cdot(R)=K \cdot R^{-n}
$$

Then from the Equation (8) for the derivation $v(R)$ we obtain

$$
v \cdot(R)=-n \cdot K \cdot R^{-n-1}
$$

which may be written in the form

$$
v \cdot(R)=-\frac{n}{R} \cdot K \cdot R^{-n}
$$

Having in mind Equation (8), from the Equation (10) we obtain

$$
v \cdot(R)=-n \cdot \frac{v(R)}{R}
$$

If Lagrange's equation is applied to the function $v(R)$ from (8) in the final growth increment, we obtain

$$
\mathrm{v}(R+h) \approx v(R)+h \cdot v(R+\theta \cdot h), 0<\theta<1
$$

or small absolute values $h$, from (12), we obtain the relation

$$
v(R+h) \approx v(R)+h \cdot v(R)
$$

Having (11) in mind, relation (13) becomes

$$
v(R+h) \approx v(R)-n \cdot h \cdot \frac{v(R)}{R}
$$

A significant property of the equation of rock mass oscillation velocity depending on the reduced distance which is obtained from the relation (14) is as follows: if the reduced distance $R$ from any level is increased (decreased) by $1 \%$, the rock mass oscillation velocity $v$ will decrease (increase) by approximately $n \%$ [11]. 
Indeed, for $h= \pm \frac{R}{100}= \pm 1 \% R$, from (13) we obtain

$$
\begin{aligned}
& v\left(R \pm \frac{R}{100}\right) \approx v(R) \mp n \cdot \frac{R}{100} \cdot \frac{v(R)}{R} \\
& v\left(R \pm \frac{R}{100}\right) \approx v(R) \mp n \cdot \frac{v(R)}{100} \\
& v(R \pm 1 \% R) \approx v(R) \mp n \% \cdot v(R)
\end{aligned}
$$

\section{Models for determining parameters for rock mass oscilla- tion equation}

In the Equation (1) two parameters appear, $K$ and $n$, which need to be determined for a specific work environment and specific blasting conditions. It is possible to determine the parameters $K$ and $n$ in many ways, i.e., models, using the values obtained by experimental measurements.

4.1. Model 1 - Determining the parameters by applying the least square method

The Least Square Method is mainly used to obtain the parameters $K$ and $n$ which represents a common model [12].

4.2. Model 2 - Determining the parameters through the application of quotient of products of the same number of reduced distances and oscillation velocities

According to this model, determination of the parameter $n$ is based on the quotient of the product of equal number of experimental data of the rock mass oscillation velocity $v$, using the oscillation velocity equation. In this way, first, we determine the parameter $n$, and then with parameter $n$ found, we determine the parameter $K$ from the rock mass oscillation equation [11]. theorem

4.3. Model 3 - determining parameters by applying Lagrange's

In the rock mass oscillation velocity equation (1), parameter $n$ may be determined by consecutive approximations with applying Lagrange's theorem [12].

4.4. Model 4 - determining parameters by applying quotient of relative increments oscillation velocity and reduced distances

Beginning with the rock mass oscillation velocity equation (1), which is derived in a different manner (Chapter 3.1), where parame- 
ter $K$, that appeared as the integration constant, we can determine from the conditions (initial condition) that for $R=R_{1}$ we get $v=v_{1}$.

Parameters and will be determined by applying experimental data of pairs $\left(R_{i}, v_{i}\right), i=1,2, \ldots, N$, provided that the curve of the rock mass oscillation velocity passes through the point $M_{1}\left(R_{1}, v_{1}\right)$. In that case out of Equation (1) for $R=R_{1}$ and $v=v_{1}$, we obtain

$$
v_{1}=K \cdot R_{1}^{-n} \rightarrow K=v_{1} \cdot R_{1}^{n}
$$

By the replacement of values for $K$ from (16) in the equation (1) we obtain the equation

$$
v=v_{1} \cdot\left(\frac{R_{1}}{R}\right)
$$

From the equation (17) for $R=R_{1}$ there is obtained $v=v_{1}$ or any $\mathrm{n}$, in our case $n>0$. For $R=R_{i}, i=2,3, \ldots, N$, from the equation (17) we can take that: $v_{i}=v_{1}\left(\frac{R_{1}}{R_{i}}\right)^{n},=2,3, \ldots, N$, from where the relation is obtained

$$
v_{1} \cdot v_{2} \cdot \ldots \cdot v_{1}^{N}\left(\frac{R_{1}^{N}}{R_{1} \cdot R_{2} \cdot \ldots \cdot R_{N}}\right)
$$

From the relation (18) we can determine parameter $n$. By logarithm operation of relation (18) we obtain

$$
n \log \left(\frac{R_{1}^{N}}{R_{1} \cdot R_{2} \cdot \ldots \cdot R_{N}}\right)=\log \left(\frac{v_{1} v_{2} \cdot \ldots \cdot v_{N}}{v_{1}^{N}}\right) ; \frac{\log \left(\frac{v_{1} v_{2} \cdot \ldots \cdot v_{N}}{v_{2}^{N}}\right)}{\log \left(\frac{R_{2}^{N}}{R_{1} \cdot R_{2} \cdot \ldots \cdot R_{N}}\right)}
$$

By the replacement of the value for the parameter $n$ in the equation (17), found in this way, we obtain the relation for the rock mass oscillation velocity in the monitored environment: $v=v_{1} \cdot\left(\frac{R_{1}}{R}\right)^{n}$. Thus, to determine the parameter $n$, all experimental data were taken into account.

4.5. Model 5 - defining parameters adopting the values of parameter $n$

Earlier numerous explorations have shown that that value of parameter $\mathrm{n}$ ranges mostly in the interval from 1 to 3 , most frequently in the interval from 1 to 2 . Taking into consideration the characteris- 
tic of the rock mass oscillation equation (Chapter 3.2.) as well as the values of parameter $n$, which is mostly in the interval from 1 to 2 , we can accept that it is $n=1,5$, which means that rock mass oscillation equation is reduced to the relation

$$
v=K \cdot R^{-1,5}
$$

From equation (20) for $K$ we get

$$
K=v \cdot R^{-1,5}
$$

For finding parameter $K$ are used data for pairs $\left(R_{m}, v_{m}\right)$, $m=1,2, \ldots, N$, from the table of experimental data, thus we arrive at

$$
K_{1}=v_{1} \cdot R_{1}^{1,5} ; \quad K_{2}=v_{2} \cdot R_{2}^{1,5} ; \ldots ; K_{N}=v_{N} \cdot R_{N}^{1,5}
$$

however, for parameter $K$ we take its arithmetical mean value.

In this way the model for solving rock mass oscillation equation has been simplified by adopting the value of parameter ${ }_{n}$.

On the basis of the calculated rock mass oscillation equation using formula (1), using various earlier mentioned models, we are able to construct the approximate curve. This curve correlates the received results of the oscillated velocities depending on applied quantity of explosive, distance from the blasting site to the monitoring place, characteristics of the working environment and conditions of blasting.

\section{Defining statistical criteria}

For the above-mentioned models 1-5, on the basis of experimental data, we can get equations that can give us the rock mass oscillation velocities $\mathrm{v}$ depending on the reduced distance $R$.

In order to evaluate the degree of connection between the registered (measured) and calculated rock mass oscillation velocities in this paper we used the coefficient of linear correlation $r[13,15]$ between the logarithms of reduced distances $R$ and logarithms of oscillation velocities $v$. Coefficient of linear correlation $r$ is also used in order to evaluate the degree of connection between values of obtained parameters $\mathrm{n}$ and $K$ for models $1-5$.

Besides, in order to evaluate the degree of connection between the reduced distances $R$ and oscillation velocities $\mathrm{v}$ we used index of the curved dependency $\rho[14,16]$.

As a convenience measure of the obtained functional relationship for the given experimental data, the criterion „3S" was also used 
[12]. This criterion uses squares of differences between the obtained experimental data and the calculated ones for oscillation velocities of $\mathrm{v}$. If those differences are one after another $\varepsilon_{1}, \varepsilon_{2}, \ldots \varepsilon_{N}$, then it is

$$
S=\sqrt{\frac{\varepsilon_{1}^{2}+\varepsilon_{2}^{2}+\ldots+\varepsilon_{N}^{2}}{N}}
$$

According to this criterion, for the evaluation of convenience of the obtained functional correlation, the following relations are valid:

- if it is $\left|\varepsilon_{\max }\right| \geq 3 S$, the obtained functional correlation is rejected as unfavorable,

- if it is $\left|\varepsilon_{\operatorname{mxx}}\right|<3 S$, the functional correlation is accepted as a good one.

\section{Review of mass blasting at the drenovac open pit \\ 6.1. General characteristics of the Drenovac open pit}

This paper includes examinations carried out during mass blasting at the Drenovac open pit, Kolubara region, central part of West Serbia. Measurements are performed at the mass or stratified limestone [17]. The physical - mechanical characteristics of the working environment are:

volume mass $\gamma=2,68 \mathrm{kN} / \mathrm{m}^{3}$,

porosity $p=0,7-1,5 \%$,

cohesion $C=0,25 \mathrm{MPa}$,

compressive strength (in dry state $\sigma_{p d}=120-134 \mathrm{MPa}$, in water saturated state $\sigma_{p w}=83-129 \mathrm{MPa}$ ),

angle of internal friction $\varphi=41^{\circ}$

\subsection{Manner of blasting operations at the Drenovac open pit}

Measurements of seismic shock waves at the Drenovac open pit carried out during blasting were conducted in order to exploit the deposit. Eight blasting operations were carried out.

The AMONEX-1 28/200, AMONEX-1 60/1000, AMONEX 60/1000, ANFO $J$ in bags of $25 \mathrm{~kg}$ and ANFEX PP 70/1500 were used as explosives. The explosive was activated in boreholes by NONEL detonators, marked $N-25 / 500$ and $K$-42 connectors while initiation is performed using electronic detonators. Basic data related to the number of boreholes, the overall explosive amount, the explo- 
sive amount by deceleration interval, overall borehole depth and average stemming length, are presented in Table 1.

Table 1

Review of blasting parameters at the Drenovac open pit

\begin{tabular}{c|c|c|c|c|c}
\hline Blasning & $N_{b}$ & $Q_{u k}[\mathrm{~kg}]$ & $Q_{i}[\mathrm{~kg}]$ & $L_{u k}[\mathrm{~m}]$ & $L_{\mathrm{c}}[\mathrm{m}]$ \\
\hline I & 27 & 661.4 & 36.2 & 211.0 & $2.8-3.0$ \\
\hline II & 28 & 1980.6 & 71.2 & 488.0 & $2.8-3.0$ \\
\hline III & 15 & 915.3 & 66.2 & 213.0 & $2.8-3.0$ \\
\hline IV & 16 & 745.0 & 47.0 & 175.0 & $3.0-3.2$ \\
\hline V & 40 & 1895.0 & 60.5 & 453.0 & $3.0-3.2$ \\
\hline VI & 22 & 1774.4 & 85.2 & 402.0 & $3.0-3.2$ \\
\hline VII & 43 & 1988.6 & 54.2 & 518.0 & $3.0-3.2$ \\
\hline VIII & 20 & 600 & 32.0 & 273.0 & $3.0-3.5$ \\
\hline
\end{tabular}

\subsection{Calculation of rock mass oscillation equation parameters at the Drenovac open pit}

Values of distance from the blasting site to the place of observation, total quantity of explosive, calculated values of reduced distances, registered values of rock mass oscillation velocities per components $v_{v}, v_{t}, v_{1}$ and resulted rock mass oscillation velocities $v_{r}$ for blastings I-VIII, at the total of seven measured points MP, are presented in Table 2.

Table 2

Review of blasting parameters and measurement results

\begin{tabular}{c|c|c|c|c|c|c|c|c|c}
\hline № & Blast & MP & $r(\mathrm{~m})$ & $Q(\mathrm{~kg})$ & $R$ & $v_{v}(\mathrm{~cm} / \mathrm{q})$ & $v_{1}(\mathrm{~cm} / \mathrm{s})$ & $v_{2}(\mathrm{~cm} / \mathrm{s})$ & $v_{v}(\mathrm{~cm} / \mathrm{s})$ \\
\hline 1 & I & MP2 & 383.87 & 661.4 & 44.0585 & 0.070 & 0.100 & 0.110 & 0.1643 \\
\hline 2 & I & MP3 & 250.49 & 661.4 & 28.7499 & 0.260 & 0.470 & 0.540 & 0.7616 \\
\hline 3 & I & MP5 & 647.42 & 661.4 & 74.3073 & 0.080 & 0.090 & 0.080 & 0.1446 \\
\hline 4 & II & MP1 & 605.54 & 1980.6 & 48.2182 & 0.060 & 0.060 & 0.070 & 0.1100 \\
\hline 5 & II & MP2 & 334.15 & 1980.6 & 26.6078 & 0.080 & 0.120 & 0.150 & 0.2081 \\
\hline 6 & II & MP3 & 256.71 & 1980.6 & 28.4042 & 0.510 & 0.500 & 1.090 & 1.3031 \\
\hline 7 & II & MP6 & 527.05 & 1980.6 & 41.9681 & 0.090 & 0.230 & 0.160 & 0.2943 \\
\hline 8 & III & MP1 & 616.35 & 915.3 & 63.4804 & 0.091 & 0.083 & 0.082 & 0.1482 \\
\hline 9 & III & MP2 & 250.14 & 915.3 & 25.7629 & 0.192 & 0.573 & 0.719 & 0.9392 \\
\hline 10 & III & MP3 & 412.66 & 915.3 & 42.5015 & 0.380 & 0.605 & 0.412 & 0.8247 \\
\hline 11 & III & MP5 & 714.10 & 915.3 & 73.5481 & 0.138 & 0.096 & 0.116 & 0.2045 \\
\hline 12 & III & MP6 & 541.13 & 915.3 & 55.7332 & 0.170 & 0.241 & 0.177 & 0.3454 \\
\hline 13 & III & MP7 & 530.89 & 915.3 & 54.6785 & 0.133 & 0.236 & 0.193 & 0.3326 \\
\hline
\end{tabular}




\begin{tabular}{c|c|c|c|c|c|c|c|c|c}
\hline № & Blast & MP & $r(\mathrm{~m})$ & $Q(\mathrm{~kg})$ & $R$ & $v_{v}(\mathrm{~cm} / \mathrm{q})$ & $v_{1}(\mathrm{~cm} / \mathrm{s})$ & $v_{2}(\mathrm{~cm} / \mathrm{s})$ & $v_{v}(\mathrm{~cm} / \mathrm{s})$ \\
\hline 14 & IV & MP1 & 723.77 & 745.0 & 79.8390 & 0.060 & 0.080 & 0.070 & 0.1221 \\
\hline 15 & IV & MP2 & 410.33 & 745.0 & 45.2635 & 0.140 & 0.170 & 0.180 & 0.2844 \\
\hline 16 & IV & MP3 & 223.89 & 745.0 & 24.6973 & 0.310 & 0.420 & 0.540 & 0.7511 \\
\hline 17 & IV & MP5 & 644.64 & 745.0 & 71.1102 & 0.110 & 0.200 & 0.200 & 0.3035 \\
\hline 18 & IV & MP7 & 426.38 & 745.0 & 47.0339 & 0.200 & 0.230 & 0.210 & 0.3701 \\
\hline 19 & V & MP1 & 737.38 & 1895.0 & 60.0667 & 0.050 & 0.070 & 0.040 & 0.0948 \\
\hline 20 & V & MP3 & 210.96 & 1895.0 & 17.1847 & 0.550 & 0.790 & 1.150 & 1.4996 \\
\hline 21 & V & MP7 & 422.53 & 1895.0 & 34.4192 & 0.210 & 0.360 & 0.320 & 0.5254 \\
\hline 22 & VI & MP3 & 231.44 & 1774.4 & 19.1171 & 0.577 & 1.160 & 0.709 & 1.4768 \\
\hline 23 & VI & MP5 & 650.53 & 1774.4 & 53.7341 & 0.055 & 0.071 & 0.077 & 0.1165 \\
\hline 24 & VI & MP6 & 640.06 & 1774.4 & 52.8693 & 0.081 & 0.150 & 0.168 & 0.2393 \\
\hline 25 & VI & MP7 & 425.36 & 1774.4 & 35.1350 & 0.340 & 0.465 & 0.259 & 0.6316 \\
\hline 26 & VII & MP3 & 333.13 & 1988.6 & 26.4910 & 0.534 & 0.460 & 0.602 & 0.9268 \\
\hline 27 & VII & MP6 & 530.48 & 1988.6 & 42.1845 & 0.101 & 0.190 & 0.150 & 0.2623 \\
\hline 28 & VII & MP7 & 415.31 & 1988.6 & 33.0260 & 0.284 & 0.525 & 0.286 & 0.6618 \\
\hline 29 & VIII & MP1 & 609.20 & 600.0 & 72.2286 & 0.030 & 0.070 & 0.070 & 0.1034 \\
\hline 30 & VIII & MP3 & 387.35 & 600.0 & 45.9254 & 0.339 & 0.527 & 0.629 & 0.8878 \\
\hline 31 & VIII & MP6 & 532.35 & 600.0 & 63.1171 & 0.067 & 0.112 & 0.079 & 0.1607 \\
\hline 32 & VIII & MP7 & 493.85 & 600.0 & 58.5524 & 0.072 & 0.157 & 0.156 & 0.2327 \\
\hline
\end{tabular}

Based on data given in Table 2 , the rock mass oscillation equation is calculated by the formula (1) - for the models 1 and 2 .

The calculation of the curve was carried out for values of reduced distances from $R=17,1847$ to $R=79,8390$. Thus, curve parameters were calculated enabling us to determine the equation of rock mass oscillation for models $1-5$ in the form of

$$
\text { Model } 1 \quad v_{1}=166,3916 \cdot R^{-1,6433}
$$

thus between $\log v_{\mathrm{r}}$ and $\log R$ we get linear dependency that is expressed by equation (24) with the coefficient of linear dependency $r_{\log }$ which is: $r_{\log }=-0,8003$.

Graphic review of the rock mass oscillation equation is shown in fig. 2 . 


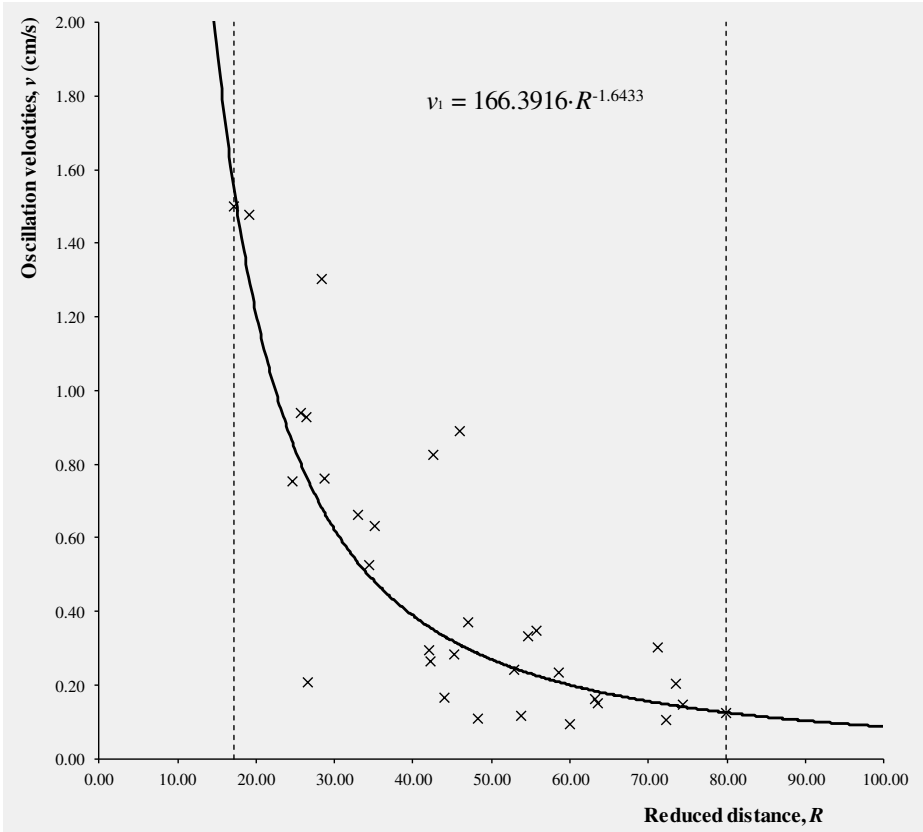

Fig. 2. Graphic review of oscillation velocity and reduced distance at the Drenovac open pit

Model 2

$$
\begin{aligned}
& v_{2}=172,4630 \cdot R^{-1,6214} \\
& v_{3}=58,2539 \cdot R^{-1,3311} \\
& v_{4}=143,2699 \cdot R^{-1,6032} \\
& v_{5}=109,3704 \cdot R^{-1,5}
\end{aligned}
$$

On the basis of the obtained equations for rock mass oscillation (24), (25), (26), (27) and (28) it is possible to calculate values of rock mass oscillation velocities for the corresponding reduced distances for models 1-5.

In table 3, the review of reduced distances $R$, registered rock mass oscillation velocities $v_{r}$ is given, as well as calculated rock mass oscillation velocities from $v_{i 1}$ to $v_{i s}$, for models 1-5. 
Table 3

Review of registered and calculated rock mass oscillation velocities for models 1-5

\begin{tabular}{|c|c|c|c|c|c|c|c|}
\hline № & $R$ & $v_{r}(\mathrm{~cm} / \mathrm{s})$ & $v_{i 2}(\mathrm{~cm} / \mathrm{s})$ & $v_{i 2}(\mathrm{~cm} / \mathrm{s})$ & $v_{i 3}(\mathrm{~cm} / \mathrm{s})$ & $v_{i 4}(\mathrm{~cm} / \mathrm{s})$ & $v_{i 5}(\mathrm{~cm} / \mathrm{s})$ \\
\hline 1 & 17.1847 & 1.4996 & 1.5539 & 1.7141 & 1.3220 & 1.4996 & 1.5353 \\
\hline 2 & 19.1171 & 1.4768 & 1.3043 & 1.4421 & 1.1472 & 1.2641 & 1.3085 \\
\hline 3 & 24.6973 & 0.7511 & 0.8562 & 0.9520 & 0.8158 & 0.8384 & 0.8911 \\
\hline 4 & 25.7629 & 0.9392 & 0.7988 & 0.8890 & 0.7712 & 0.7835 & 0.8364 \\
\hline 5 & 26.4910 & 0.9268 & 0.7631 & 0.8497 & 0.7431 & 0.7493 & 0.8021 \\
\hline 6 & 26.6078 & 0.2081 & 0.7576 & 0.8437 & 0.7387 & 0.7440 & 0.7969 \\
\hline 7 & 28.4042 & 1.3031 & 0.6804 & 0.7589 & 0.6772 & 0.6700 & 0.7225 \\
\hline 8 & 28.7499 & 0.7616 & 0.6670 & 0.7442 & 0.6664 & 0.6572 & 0.7095 \\
\hline 9 & 33.0260 & 0.6618 & 0.5311 & 0.5943 & 0.5541 & 0.5262 & 0.5763 \\
\hline 10 & 34.4192 & 0.5254 & 0.4963 & 0.5558 & 0.5244 & 0.4924 & 0.5416 \\
\hline 11 & 35.1350 & 0.6316 & 0.4798 & 0.5376 & 0.5103 & 0.4765 & 0.5252 \\
\hline 12 & 41.9681 & 0.2943 & 0.3583 & 0.4030 & 0.4028 & 0.3583 & 0.4023 \\
\hline 13 & 42.1845 & 0.2623 & 0.3552 & 0.3996 & 0.4000 & 0.3554 & 0.3992 \\
\hline 14 & 42.5015 & 0.8247 & 0.3509 & 0.3948 & 0.3961 & 0.3512 & 0.3947 \\
\hline 15 & 44.0585 & 0.1643 & 0.3307 & 0.3724 & 0.3775 & 0.3315 & 0.3740 \\
\hline 16 & 45.2635 & 0.2844 & 0.3164 & 0.3565 & 0.3642 & 0.3174 & 0.3592 \\
\hline 17 & 45.9254 & 0.8878 & 0.3089 & 0.3482 & 0.3572 & 0.3101 & 0.3514 \\
\hline 18 & 47.0339 & 0.3701 & 0.2971 & 0.3350 & 0.3461 & 0.2985 & 0.3391 \\
\hline 19 & 48.2182 & 0.1100 & 0.2852 & 0.3218 & 0.3348 & 0.2868 & 0.3267 \\
\hline 20 & 52.8693 & 0.2393 & 0.2451 & 0.2771 & 0.2962 & 0.2475 & 0.2845 \\
\hline 21 & 53.7341 & 0.1165 & 0.2387 & 0.2699 & 0.2899 & 0.2411 & 0.2777 \\
\hline 22 & 54.6785 & 0.3326 & 0.2319 & 0.2624 & 0.2832 & 0.2345 & 0.2705 \\
\hline 23 & 55.7332 & 0.3454 & 0.2248 & 0.2544 & 0.2761 & 0.2274 & 0.2629 \\
\hline 24 & 58.5524 & 0.2327 & 0.2073 & 0.2349 & 0.2586 & 0.2101 & 0.2441 \\
\hline 25 & 60.0667 & 0.0948 & 0.1987 & 0.2253 & 0.2499 & 0.2017 & 0.2349 \\
\hline 26 & 63.1171 & 0.1607 & 0.1832 & 0.2079 & 0.2340 & 0.1863 & 0.2181 \\
\hline 27 & 63.4804 & 0.1482 & 0.1815 & 0.2060 & 0.2322 & 0.1846 & 0.2162 \\
\hline 28 & 71.1102 & 0.3035 & 0.1506 & 0.1714 & 0.1966 & 0.1539 & 0.1824 \\
\hline 29 & 72.2286 & 0.1034 & 0.1468 & 0.1671 & 0.1955 & 0.1501 & 0.1782 \\
\hline 30 & 73.5481 & 0.2045 & 0.1425 & 0.1623 & 0.1909 & 0.1458 & 0.1734 \\
\hline 31 & 74.3073 & 0.1446 & 0.1401 & 0.1596 & 0.1833 & 0.1434 & 0.1707 \\
\hline 32 & 79.8390 & 0.1221 & 0.1245 & 0.1421 & 0.1711 & 0.1278 & 0.1533 \\
\hline
\end{tabular}

Fig. 3 shows a graphic review of the coefficients of the linear dependency between registered and calculated rock mass oscillation velocities for models $1-5$. 


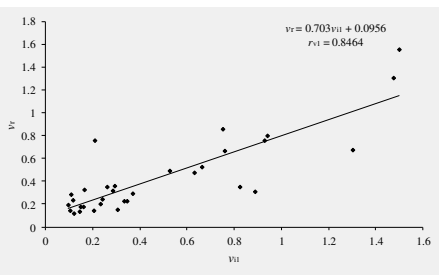

a)

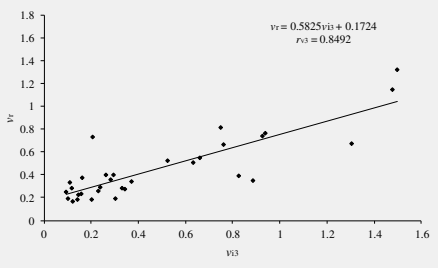

c)

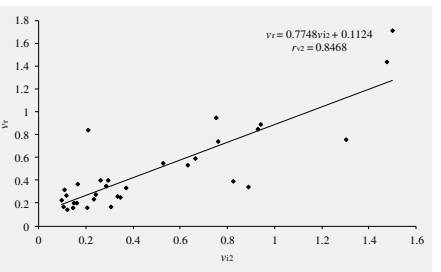

b)

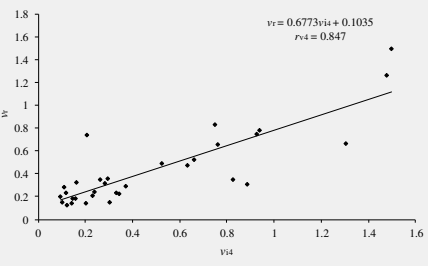

d)

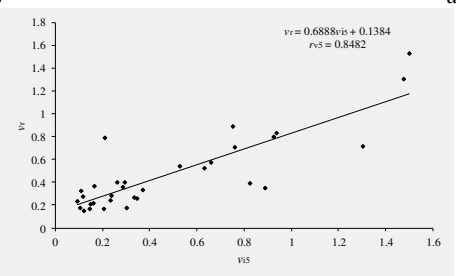

e)

Fig. 3. Graphic review of the coefficients of the linear dependency between registered and calculated oscillation velocities for: $a$ ) model $1, b$ ) model $2, c)$ model 3 , d) model 4 and $e$ ) model 5

In table 4, review of reduced distances $R$, registered rock mass oscillation velocities $v_{r}$ is given as well as the differences between registered and calculated oscillation velocities for models 1-5.

Table 4

Review of differences between registered and calculated rock mass oscillation velocities for models 1-5

\begin{tabular}{c|c|c|c|c|c|c|c}
\hline № & $R$ & $v_{r}(\mathrm{~cm} / \mathrm{s})$ & $v_{r}-v_{i 1}$ & $v_{r}-v_{i 2}$ & $v_{r}-v_{i 3}$ & $v_{r}-v_{i 4}$ & $v_{\mathrm{r}}-v_{i 5}$ \\
\hline 1 & 17.1847 & 1.4996 & -0.0543 & -0.2145 & 0.1776 & 0.0000 & -0.0357 \\
\hline 2 & 19.1171 & 1.4768 & 0.1725 & 0.0347 & 0.3296 & 0.2127 & 0.1683 \\
\hline$\ldots$ & $\ldots$ & $\ldots$ & $\ldots$ & $\ldots$ & $\ldots$ & $\ldots$ & $\ldots$ \\
\hline 3 & 79.8390 & 0.1221 & -0.0024 & -0.0200 & -0.0490 & -0.0057 & -0.0312 \\
\hline
\end{tabular}


Based on data from table 4, a statistical analysis has been done and following values have been obtained:

\section{for Model 1:}

The curved line dependency index $\rho_{1}$ between the reduced distance $R$ and rock mass oscillation velocity $v$, is:

$\rho_{1}=0,8380$ (there is a strong correlation between $R$ and $v$, given in the Equation (24)).

Maximal difference between registered and calculated rock mass oscillation velocities $\left(\varepsilon_{\max 1}\right)=\max \left|\varepsilon_{1}\right|$, is:

$$
\left(\varepsilon_{\max 1}\right)=0,6227, \mathrm{~S}_{1}-0,2200,3 S_{1}=0,6600,
$$

Since $\left(\varepsilon_{\max 1}<3 S_{1}\right.$, this supposed functional relation is accepted as a correct one.

\section{for Model 2:}

$\rho_{2}=0,8439$ ((there is a strong correlation between $R$ and $v$, given in the Equation (25)).

$$
\left(\varepsilon_{\max 2}\right)=0,6356, \mathrm{~S}_{2}-0,2163,3 \mathrm{~S}_{2}=0,6488 .
$$

$\left(\varepsilon_{\max 2}<3 S_{2}\right.$ (supposed functional relation is accepted as a correct one).

\section{for Model 3:}

$\rho_{3}=0,8303$ ((there is a strong correlation between $R$ and $v$, given in the Equation (26)).

$$
\left(\varepsilon_{\max 3}\right)=0,6259, S_{3}-0,2247,3 S_{3}=0,6741 \text {. }
$$

$\left(\varepsilon_{\max 3}<3 S_{3}\right.$ (supposed functional relation is accepted as a correct one).

\section{for Model 4:}

$\rho_{4}=0,8357$ (there is a strong correlation between $R$ and $v$, given in the Equation (27)).

$$
\left(\varepsilon_{\max 4}\right)=0,6331, S_{4}-0,2214,3 S_{4}=0,6642 .
$$

( $\varepsilon_{\max 4}<3 S_{4}$ (supposed functional relation is accepted as a correct one).

\section{for Model 5:}

$\rho_{5}=0,8469$ (there is a strong correlation between $R$ and $v$, given in the Equation (28)).

$$
\left(\varepsilon_{\max 5}\right)=0,5888, S_{5}-0,2144,3 S_{5}=0,6431 .
$$

$\left(\varepsilon_{\max 4}<3 \mathrm{~S}_{5}\right.$ (supposed functional relation is accepted as a correct one). 
Based on the obtained values for parameters $n$ and $K$ in the rock mass oscillation equations, by application of the mentioned five models, the linear dependency between $n$ and $K$ form has been determined.

$$
K=358,7443 \cdot n-422,4447
$$

With coefficient of the linear dependency which is: $r_{p}=0,982$

Based on the values of the coefficient of linear dependency $r_{p}$ between parameters $n$ and $K$ for all five models, we can say that there is a strong correlation between parameters $n$ and $K$.

\section{Conclusion}

To establish the relationship between the rock mass oscillation velocity of the and basic parameters affecting its magnitude, being: the quantity of explosive, the distance from the blasting site, characteristics of the rock mass and the type of blasting, it is the equation of M. A. Sadovskii that is used most commonly. In this paper, parameters $n$ and $K$ from Sadovskii's equation were determined in five ways - models in the given work environment. Their corresponding functions have been obtained presenting rock mass oscillation velocities of the depending on a reduced distance. The calculated corresponding indexes of the curved line correlation point out that there is a rather strong curved line relationship between a reduced distance and the rock mass oscillation velocity expressed in the obtained functions.

The relation between parameters $K$ and $n$ has been obtained in this study. This relation made it possible to find the value of the second parameter for the given determined value of one parameter. In practice it is simpler to determine the value of the parameter $K$ in advance for an adopted value of the parameter $n$ in the interval from $1-2$, as has been applied in model 5 . In this way, a new simplified formula has been obtained for determining the rock mass oscillation velocity equation in which only parameter $K$ is calculated.

Comparing values of the recorded oscillation velocities of the rock mass with the corresponding calculated ones, it can be seen that they are approximately the same. Linear dependency with highly strong correlation has been obtained between registered and calculated values of rock mass oscillation velocities. On the basis of the obtained coefficients of the linear dependency, we can conclude that all five models can be used for calculating the rock mass oscillation velocity. 
From the obtained formulas for determining rock mass oscillation velocity by models $1-5$, we can see that at higher values of parameter $n$ they get higher values of parameter $K$ and vice versa, whereby we established that there is a highly strong linear dependency between them. These facts confirm once again that all models mentioned above can be used for calculating the rock mass oscillation velocity.

\section{References}

[1] Yao Q., Yang X., Li H. (2017); Development of Absorbed Blasting Vibration Energy Index for the Evaluation of Human Comfort in Multistorey Buildings, Shock and Vibration, 2017, Article ID 9567657, 12 pages, DOI: https://doi.org/10.1155/2017/9567657

[2] Zhang Z. Y., Zhang W. X., Wu X. X. (2003); Modern Hydraulic Engineering Blasting, China Water Power Press, Beijing, China

[3] Stanković S., Dobrilović M., Bohanek V. (2017); A Practical Approach to the Ground Oscillation Velocity Measurement Method, The Mining-GeologyPetroleum Engineering Bulletin, DOI: 10.17794/rgn.2017.4.6

[4] Qiang Y., Xingguo Y., Hongtao L. (2017); A Method for Evaluating the Comfort During Blasting Vibration Based on Energy Absorbing Principle, Journal of Vibration and Control, DOI: https://doi.org/10.1177/1077546316685680

[5] Yu L. (2015); Safety Influence of Blasting Vibration on Multistory Building, Journal of Railway Engineering Society, 32 (3), 86-89

[6] Ma L., Li K., Xiao S., Ding X., Chinyanta S. (2016); Research on Effects of Blast Casting Vibration and Vibration Absorption of Presplitting Blasting in Open Cast Mine, Shock and Vibration, Article ID 4091732, 9 pages, (2016), DOI: https://doi.org/10.1155/2016/4091732

[7] Kuzu C., Guclu E. (2009); The Problem of Human Response to Blast Induced Vibrations in Tunnel Construction and Mitigation of Vibration Effects Using Cautious Blasting in Half-Face Blasting Rounds, Tunnelling and Underground Space Technology, 24 (1), 53-61, DOI: 10.1016/j.tust.2008.02.001

[8] Li D. D., Deng Z. D. (2012); Evaluation of the Effects of Blasting Vibration on Humans in the Excavation of CMICT Dock, Engineering Blasting, 12 (2), 82-85

[9] Medvedev S.V. (1964); Seismics of Mountainous Explosions, Nedra, Moscow, Russia, 42-43,

[10] Lutovac S., Vidanović N., Beljić Č., Gligorić Z. (2015); Soil Oscillation Law Parameter Determination with the Application of Lagrange's Theorem at the "Kovilovača" Open Pit, Mining Metallurgy Engineering Bor, 3, 53-62, DOI: $10.5937 / \mathrm{mmeb} 15030531$

[11] Lutovac S., Gluščević B., Tokalić R., Majstorović J., Beljić Č. (2018); Models of Determining the Parameters of Rock Mass Oscillation Equation with Experimental and Mass Blastings, Minerals, 8 (2), 70, DOI: https://doi.org/10.3390/min8020070

[12] Simeunović D. (1985); Mathematics, Faculty of Mining and Geology, Mining Department, Belgrade, Serbia, 101-103 
[13] Mukaka M., (2012); A Guide to Appropriate Use of Correlation Coefficient in Medical Research, Malawi Med. J., 24 (3), 69-71

[14] Wang T., Zhang S. (2011); Study on Linear Correlation Coefficient and Nonlinear Correlation Coefficient in Mathematical Statistics, Studies in Mathematical Sciences, 3 (1), 58-63, DOI: 10.3968/j.sms.1923845220110301.4Z483

[15] Smith R. (2015); A Mutual Information Approach to Calculating Nonlinearity, Stat, 4, 291-303, DOI: 10.100X/sta.0000

[16] Guerard J. (2013); Introduction to Financial Forecasting in Investment Analysis, Springer, New York, DOI:10.1007/978-1-4614-5239-3

[17] Trajković S., Lutovac S., Katona O. (2009); Study of Seismic and Air Impacts on the Surrounding Building Structures as the Result of Blasting at the Open Pit "Drenovac" Near Mionica, Faculty of Mining and Geology, Belgrade, 34(A), 15-51(B) (in Serbian).

https://doi.org/10.31713/m1112

\section{BITUMEN EXTRACTION TECHNOLOGY FROM BITUMINOUS SAND DEPOSITS}

Yelchenko-Lobovska A.S.

National University «Yuri Kondratyuk Poltava Polytechnic»,

PhD Student, Ukraine

\section{Lavryk I.O.}

National University «Yuri Kondratyuk Poltava Polytechnic»,

PhD Student, Ukraine

Liashenko A.V.

National University «Yuri Kondratyuk Poltava Polytechnic», senior lecturer, Ukraine

Pedchenko L.O.

National University «Yuri Kondratyuk Poltava Polytechnic», $\mathrm{PhD}$, Ukraine

\section{Pedchenko M.M.}

National University «Yuri Kondratyuk Poltava Polytechnic», $\mathrm{PhD}$, Ukraine

\footnotetext{
Abstract

Today considerable experience in the development of tar sands is accumulated. However, well-known mining technologies do not cover the entire depth range of natural bitumen deposits. In addition, there are significant energy-intensive technol-
} 